\title{
miR-371-5p suppresses the proliferative and migratory capacity of human nasopharyngeal carcinoma by targeting BCL2
}

\author{
BIFAN DENG $^{1}$, FEIQUN SU ${ }^{2}$, RUIBIN XIE $^{3}$ and WEIGUANG TANG ${ }^{4}$ \\ Departments of ${ }^{1}$ Otorhinolaryngology, Head and Neck Surgery, ${ }^{2}$ Nursing, ${ }^{3}$ Cardiovascular Medicine and \\ ${ }^{4}$ Nephrology and Rheumatology, Hezhou Renmin Hospital, Hezhou, Guangxi 542899, P.R. China
}

Received April 16, 2017; Accepted February 27, 2018

DOI: $10.3892 / \mathrm{ol} .2018 .8481$

\begin{abstract}
The aim of the present study was to investigate the expression and function of microRNA (miR)-371-5p in nasopharyngeal carcinoma (NPC). The levels of miR-371-5p were analyzed in nasopharyngeal epithelium tissues, NPC tissues, human NPC cell lines and NP69 cells using reverse transcription-quantitative polymerase chain reaction analysis. The association between the level of miR-371-5p and clinicopathological variables was also investigated. Cell proliferation was determined using an MTT assay, and the activities of cell metastasis were determined using wound healing and Transwell migration assays. To assess whether miR-371-5p can combine with the targeting sequence of B-cell lymphoma 2 (BCL2) mRNA or not, a luciferase activity assay was performed. An animal experiment was used to examine the effect of miR-371-5p on the development of NPC. The results revealed that the expression of miR-371-5p was reduced in NPC samples and NPC cells. The level of miR-371-5p was associated with clinical stage and distant metastasis in patients with NPC, and was inversely associated with the protein level of BCL-2 in NPC tissues. The upregulation of miR-371-5p reduced cell growth, migration and invasion, and inhibited carcinoma growth through targeting BCL2 mRNA. Taken together, the regulation of miR-371-5p was shown to offer potential as a novel treatment approach for NPC.
\end{abstract}

\section{Introduction}

Nasopharyngeal carcinoma (NPC) is a pernicious epithelial tumor originating from the nasopharynx, and is one of the most common types of cancer in the southern region of the People's Republic of China (1). Although anticancer therapy

Correspondence to: Dr Weiguang Tang, Department of Nephrology and Rheumatology, Hezhou Renmin Hospital, 150 Xiyue Street, Babu, Hezhou, Guangxi 542899, P.R. China

E-mail: weiguangtanghz@163.com

Key words: microRNA-371-5p, proliferation, migration, B-cell lymphoma 2, nasopharyngeal carcinoma has progressed substantially over the last few years, the survival rate of individuals with NPC remains unsatisfactory. Due to the complex etiology of NPC (2), the factors contributing to the tumorigenesis and metastasis of NPC cells require elucidation in order to benefit the identification of novel therapeutic targets involved in the progression of NPC.

MicroRNAs (miRNAs) represent a type of short-sequence RNA, which regulate gene or protein levels via combining directly with the target mRNA (3). They are involved in the cell growth, differentiation, apoptosis and metastasis of cells $(4,5)$. Several studies have identified that functional disorder of miRNAs is involved in the abnormal growth of several types of malignant tumor (6-8), and microRNAs may serve as important regulators in NPC treatment (9-11). As an important functional microRNA, microRNA (miR)-371-5p exerts pro- and anti-tumor effects in different types of tumor. For example, the upregulation of miR-371-5p has been identified to inhibit the malignant behavior of colorectal cancer via regulating superoxide dismutase 2 (12), however, others have demonstrated that the overexpression of miR-371-5p enhances pancreatic tumor growth via inhibitor of growth protein 1 (13) and human hepatocellular carcinoma cell proliferation by inhibiting the expression of pre-mRNA processing factor 4 homolog B (14). It is possible that miR-371-5p has different roles in diverse tumor cells. To date, the function of miR-371-5p in the development of NPC remains to be fully elucidated.

The mechanism involved in the avoidance of apoptosis is complex (15), and the overexpression of genes and proteins, which inhibit apoptosis, may be vital in this mechanism. B-cell lymphoma 2 (BCL2) acts as an influential factor in favoring cell survival by inhibiting cell apoptosis $(16,17)$. The upregulation of BCL2 in malignant tumors has been confirmed previously (18). The function of miR-371-5p in the development of NPC via regulating the level of BCL2 was investigated in the present study.

\section{Materials and methods}

Clinical tissues and cell culture. A total of 78 NPC samples and 30 nasopharyngeal epithelium samples were obtained from the Department of Otorhinolaryngology, Hezhou Renmin Hospital (Hezhou, China) from March 2013 until November 2016. None of the patients had received radiation 
therapy or chemotherapy prior to resection. Written informed consent was obtained from the individuals with NPC. The clinicopathological features of the patients are presented in Table I. The Ethics Committee of Hezhou Renmin Hospital ratified all written agreement according to the Declaration of Helsinki (2004). The 5-8F cell line, 6-10B cell line and nasopharyngeal-derived NP69 cell line were obtained from Type Culture Collection of the Chinese Academy of Sciences (Shanghai, China) and were incubated in RPMI-1640 (Invitrogen; Thermo Fisher Scientific, Inc., Waltham, MA, USA) with $10 \% \mathrm{FBS}, 100 \mathrm{U} / \mathrm{ml}$ streptomycin and $100 \mathrm{U} / \mathrm{ml}$ penicillin at $37^{\circ} \mathrm{C}$ in $5 \% \mathrm{CO}_{2}$.

RNA isolation and reverse transcription-quantitative polymerase chain reaction $(R T-q P C R)$ analysis. The RNA was extracted from the patient samples and all cell lines using TRIzol reagent (Invitrogen; Thermo Fisher Scientific, Inc.). RT-qPCR analysis was utilized to detect the levels of miR-371-5p and the levels of U6 using the TaqMan reverse transcription kit and TaqMan miRNA assay kit according to the manufacturer's instructions. U6 was used as a control for normalization; primers used are listed in Table II. A total of $1 \mu \mathrm{g}$ RNA was reverse-transcribed into cDNA. PCR was performed with the following thermocycling conditions: Initial denaturation at $95^{\circ} \mathrm{C}$ for $5 \mathrm{~min}$, followed by 40 cycles of denaturation at $95^{\circ} \mathrm{C}$ for $15 \mathrm{sec}$ and annealing at $60^{\circ} \mathrm{C}$ for $30 \mathrm{sec}$. The products were identified by melting curve analysis. Fold changes were calculated through relative quantification using the $2^{-\Delta \Delta \mathrm{Cq}}$ method (19). Experiments were performed in triplicate.

Cell transfection. The transfection of 5-8F cells with miR-371-5p mimics, miR-control or miR-371-5p mimics/pcDNA3.1 vector encoding BCL2 were performed using Lipofectamine 2000 (Thermo Fisher Scientific, Inc.).

MTT assay. At $48 \mathrm{~h}$ post-transfection, the $5-8 \mathrm{~F}$ cells were washed with PBS, resuspended in serum-free medium and seeded into 96 -well plates $\left(5 \times 10^{4}\right.$ cells/well). Following incubation for $1,2,3$ and 4 days at $37^{\circ} \mathrm{C}, 20 \mu \mathrm{l}$ MTT $(5 \mathrm{mg} / \mathrm{ml})$ was added to the culture for $4 \mathrm{~h}$. Subsequently, the cells were treated with $150 \mu \mathrm{l}$ dimethyl sulfoxide. Cell proliferation was determined by calculating the relative optical densities at $570 \mathrm{~nm}$ for each well.

Analysis of apoptosis. At $48 \mathrm{~h}$ post-transfection, the 5-8F cells were washed, resuspended, and harvested. Subsequently, staining of the cells was performed with propidium iodide and anti-Annexin V antibody (BD Biosciences, Franklin Lakes, NJ, USA). Cell apoptosis was identified using flow cytometry.

Transwell assay. A Transwell membrane coated with Matrigel (BD Biosciences) was applied to measure cell invasion. At $48 \mathrm{~h}$ post-transfection, $1 \times 10^{5}$ cells were added into the upper compartment, and medium containing $20 \%$ FBS was added to the lower compartment. After $48 \mathrm{~h}$ at $37^{\circ} \mathrm{C}$, the cells on the lower side of the membranes were fixed and stained with $0.5 \%$ crystal violet, and counted under a light microscope (Olympus Corporation, Tokyo, Japan).
Wound healing assays. Following transfection, $2 \times 10^{5}$ of the transfected cells were seeded in 12 -well plates $\left(2 \times 10^{5}\right.$ cells/well $)$ and cultured at $37^{\circ} \mathrm{C}$. On reaching $100 \%$ confluence, a wound was created by scratching the cell surface with a pipette tip, following by washing three times in medium and incubation in RPMI-1640 with $10 \%$ FBS. The wounds were observed under a light microscope at 0 and $48 \mathrm{~h}$ (Olympus Corporation). The cell migration capability was determined by subtracting the final wound width from the initial wound width.

Western blot analysis. At $48 \mathrm{~h}$ post-transfection, the cells were washed and lysed with M-PER protein extraction reagent (Pierce; Thermo Fisher Scientific, Inc.) Protease inhibitors were added to the lysates and the cell lysate centrifuged for $15 \mathrm{~min}$ at $12,000 \mathrm{x} \mathrm{g}$, and $4^{\circ} \mathrm{C}$. A bicinchoninic acid protein assay was performed to measure the protein concentration. Proteins ( $80 \mu \mathrm{g} /$ lane) were separated by $12 \%$ SDS-PAGE and transferred to polyvinylidene fluoride membranes. Membranes were blocked with 5\% dry skim milk for $1 \mathrm{~h}$ at room temperature and probed with the following primary antibodies overnight at $4^{\circ} \mathrm{C}$ : BCL2 antibody (1:500; cat. no. 2872; Cell Signaling Technology, Inc., Danvers, MA, USA), cleaved caspase-3 antibody (1:500; cat. no. ab32042; Abcam, Cambridge, UK), cleaved caspase-9 antibody (1:500; cat. no. ab2324; Abcam), $\beta$-actin antibody (1:1,000; cat. no. sc-47778; Santa Cruz Biotechnology, Inc., Dallas, TX, USA). Horseradish peroxidase-conjugated secondary antibodies (1:5,000; cat. nos. sc-2357 and sc-2005; Santa Cruz Biotechnology, Inc.) were subsequently incubated with the membranes at room temperature for $1 \mathrm{~h}$. An ECL chemiluminescent kit (EMD Millipore, Billerica, MA, USA) was used to detect the protein bands. Band density was analyzed with FluorChem FC3 gel imaging software (version 3.4; ProteinSimple; Bio-Techne, Minneapolis, MN, USA).

Luciferase reporter assay. A luciferase reporter plasmid was established through cloning the 3'-UTR of BCL2 or the mutated sequence into the pMIR-Report construct (Ambion; Thermo Fisher Scientific, Inc.). The miR-371-5p mimics, or the corresponding control were transfected together with a reporter plasmid and pRL-SV40 (Promega Corporation, Madison, WI, USA) into 5-8F cells. After $48 \mathrm{~h}$, the luciferase activity was measured using the Luciferase Reporter Assay system (Promega Corporation) in accordance with the manufacturer's protocol.

Nude mouse models. Female nude mice ( $\mathrm{n}=6 ; 25-30 \mathrm{~g} ; 6$ week old) were obtained from and housed in the Laboratory Animal Center of Guangxi Medical University (Nanning, China). Nude mice were maintained in a $12 \mathrm{~h} \mathrm{light/dark}$ cycle at $22-25^{\circ} \mathrm{C}$ with $50-60 \%$ humidity, with free access to food and water in a specific pathogen-free laboratory animal facility. Stably transfected $5-8 \mathrm{~F}$ cells $\left(1 \times 10^{7}\right)$ were subcutaneously injected into the flank of female nude mice. The mice were sacrificed on day 5, 10, 15, 20 and 25, and the weight and volume of the tumors were measured.

Statistical analysis. SPSS software 15.0 (SPSS, Inc., Chicago, IL, USA) was used for statistical analyses. Student's t-test and one-way analysis of variance were performed to analyze 
Table I. Association between the clinicopathological features of patients and level of miR-371-5p in nasopharyngeal cancer.

\begin{tabular}{lcccc}
\hline & & \multicolumn{3}{c}{$\begin{array}{c}\text { miR-371-5p } \\
\text { expression }\end{array}$} \\
Characteristic & $\begin{array}{c}\text { Patients } \\
\text { (n) } \mathrm{N}=78\end{array}$ & High & Low & P-value \\
\hline Age (years) & & & & \\
$\leq 40$ & 43 & 24 & 19 & 0.255 \\
$>40$ & 35 & 15 & 20 & \\
Sex & & & & \\
Male & 40 & 19 & 21 & 0.453 \\
Female & 38 & 20 & 18 & \\
TNM stage & & & & \\
I+II & 23 & 18 & 5 & $0.001^{\mathrm{a}}$ \\
III+IV & 55 & 21 & 34 & \\
Distant metastasis & & & & \\
No & 51 & 31 & 20 & $0.009^{\mathrm{a}}$ \\
Yes & 27 & 8 & 19 & \\
\hline
\end{tabular}

${ }^{a} \mathrm{P}<0.05$ indicates statistical significance. TNM, tumor-nodemetastasis.

the difference between groups and multiple comparisons. Pearson's $\chi^{2}$ test was performed to analyze the correlation between the level of miR-371-5p and the protein level of BCL2. A Kaplan-Meier plot was performed to analyze the overall survival of patients with NPC. All data are expressed as he mean \pm standard deviation. $\mathrm{P}<0.05$ was considered to indicate a statistically significant difference.

\section{Results}

Downregulation of miR-371-5p in nasopharyngeal carcinoma samples and cells. The level of miR-371-5p in nasopharyngeal carcinoma samples was significantly reduced, compared with that in normal tissue $(\mathrm{P}<0.001$; Fig. $1 \mathrm{~A})$. The level of miR-371-5p was significantly decreased in the two NPC cell lines, compared with that in the NP69 cell line $(5-8 \mathrm{~F}, \mathrm{P}<0.001$; 6-10B, P<0.001; Fig. 1B).

Levels of miR-371-5p are associated with an unfavorable prognosis in patients with NPC. According to the average level of miR-371-5p, all cases were divided into a low level group $(n=39)$ and a high level group $(n=39)$. Low expression levels of miR-371-5p were significantly associated with tumor-node-metastasis phase $(\mathrm{P}=0.001$; Table I) and metastasis $(\mathrm{P}=0.009$; Table II). The patient survival rates were significantly reduced in patients with NPC with a low level of miR-371-5p ( $\mathrm{P}<0.001$; Fig. 1C). Pearson's correlation test was applied to detect the association between the level of miR-371-5p and protein level of Bcl-2 in NPC samples. An inverse association was confirmed between the level of miR-219-5p and protein level of Bcl-2 in the NPC tissues (Fig. 1D). The data showed that miR-371-5p may exert an important function in NPC tumorigenesis.
Table II. Primers used in the present study.

\begin{tabular}{ll}
\hline Gene & \multicolumn{1}{c}{ Sequence $\left(5^{\prime}-3^{\prime}\right)$} \\
\hline miR-371-5p & RT: GTCGTATCCAGTGCAGGGTCCGAGG \\
& TATTCGCACTGGATACGACAGTGCC \\
& Forward: GTCGTATCCAGTGCAGCCG-CC \\
& ACTCAAACTGTGGGG \\
U6 & RT: GGGTCCGAGGTGCACTGGATACGAC \\
& AAAAT-ATGG \\
& Forward: TGCGGGTGCTCGCTTCGGCAGC
\end{tabular}

miR, microRNA; RT, reverse transcription.

Restoration of miR-371-5p suppresses the growth of 5-8F cells. The relative level of miR-371-5p was markedly increased in the miR-371-5p mimics group, compared with that in the miR-control group in 5-8F cells (Fig. 1E). The data also showed that the absorbance of $5-8 \mathrm{~F}$ cells was decreased in the miR-371-5p mimics group, compared with that in the miR-control group (Fig. 1F).

Restoration of miR-371-5p promotes the apoptosis of 5-8F cells. FACS was performed to quantify apoptosis. The $5-8 \mathrm{~F}$ cells were selected for experiments, and it was concluded that cell apoptosis was promoted by the upregulation of miR-371-5p (Fig. 2A). The present study also detected the levels of apoptosis-related proteins. The upregulation of miR-371-5p decreased the level of BCL2, and increased the levels of cleaved caspase-9 and cleaved caspase-3 (Fig. 2B). The restoration of BCL-2 partially inhibited the cell apoptosis induced by miR-371-5p.

Restoration of miR-371-5p inhibits 5-8F cell metastasis. Transwell assays and wound healing assays showed that the upregulation of miR-371-5p alleviated the migratory and invasive ability of the $5-8 \mathrm{~F}$ cells. The cotransfection of pcDNA3.1-BCL2/miR-371-5p mimics partially recovered the metastatic function of 5-8F cells, compared with the miR-371-5p group (Fig. 3A and B). The data confirmed that the overexpression of miR-371-5p functioned in the inhibition of tumor metastasis.

BCL2 $m R N A$ is a binding target of miR-371-5p. A luciferase reporter assay was utilized, as described above. The results showed that, in the wild-type, miR-371-5p inhibited luciferase reporter activity, compared with that in the miR-control group. However, no significant differences in activity were found between these two groups in the mutated type (Fig. 4A and B).

miR-371-5p inhibits tumor growth in animal experiments. The antitumor function of miR-371-5p was confirmed via animal experiments in NPC (Fig. 4C and D). The volume of tumors was reduced in the miR-371-5p mimics group, compared with that in the miR-control group. The final weight of tumors was decreased in the miR-371-5p mimics group, compared with that in the miR-control group. 
A

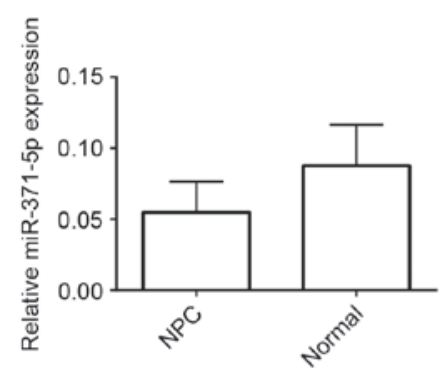

D

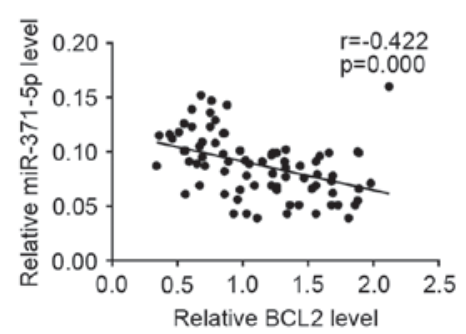

B

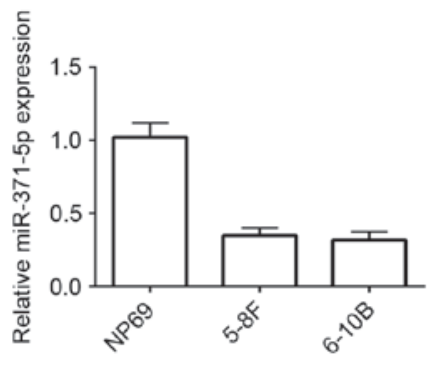

E

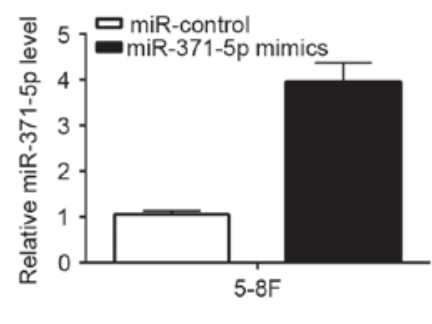

C

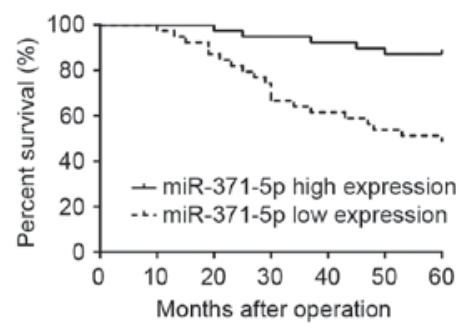

$\mathrm{F}$

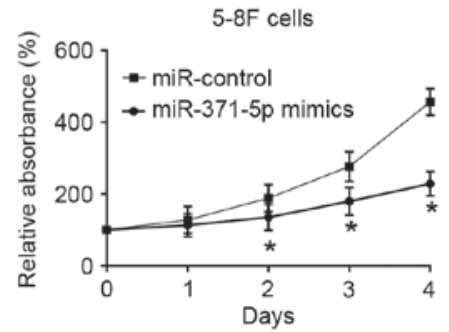

Figure 1. Expression of miR-371-5p and cell proliferation in NPC. miR-371-5p was downregulated in (A) NPC samples and (B) cells. (C) Low levels of miR-371-5p were associated with reduced overall survival rates. (D) An inverse association was confirmed between the level of miR-371-5p and protein level of BCL-2 in NPC tissues. (E) Relative levels of miR-371-5p were increased in 5-8F cells following transfection with miR-371-5p mimics. (F) Upregulation of miR-371-5p suppressed cell proliferation in 5-8F cells. "P<0.05, vs. miR-control. miR, microRNA; NPC, nasopharyngeal carcinoma; BCL2, B-cell lymphoma 2.

A
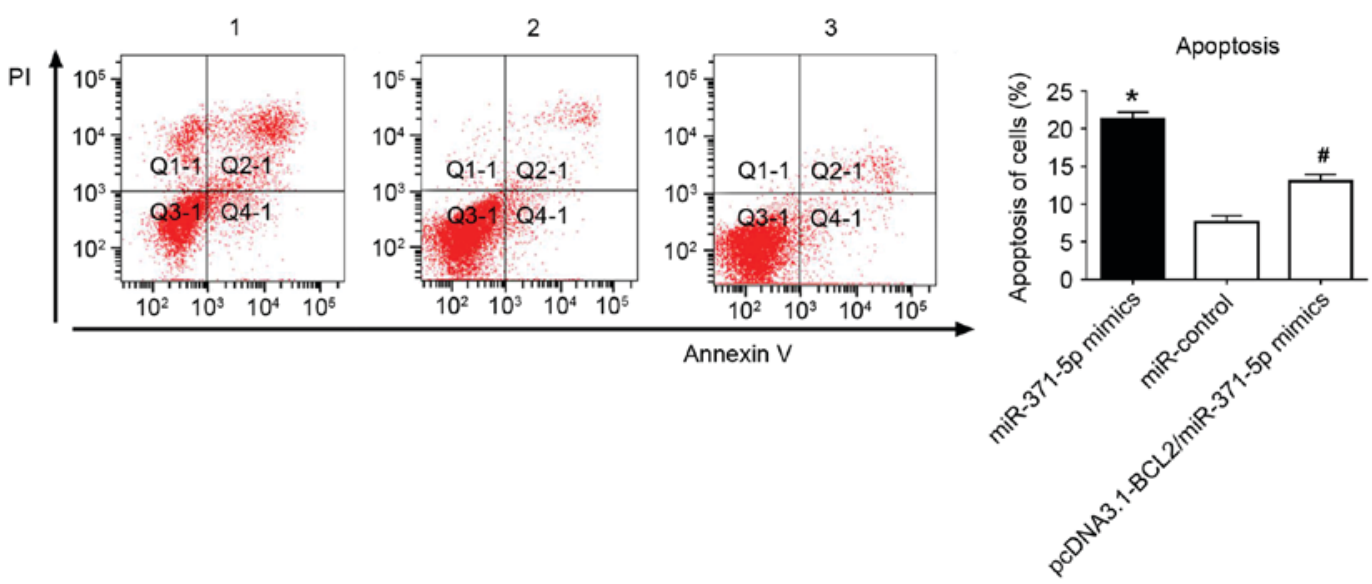

B

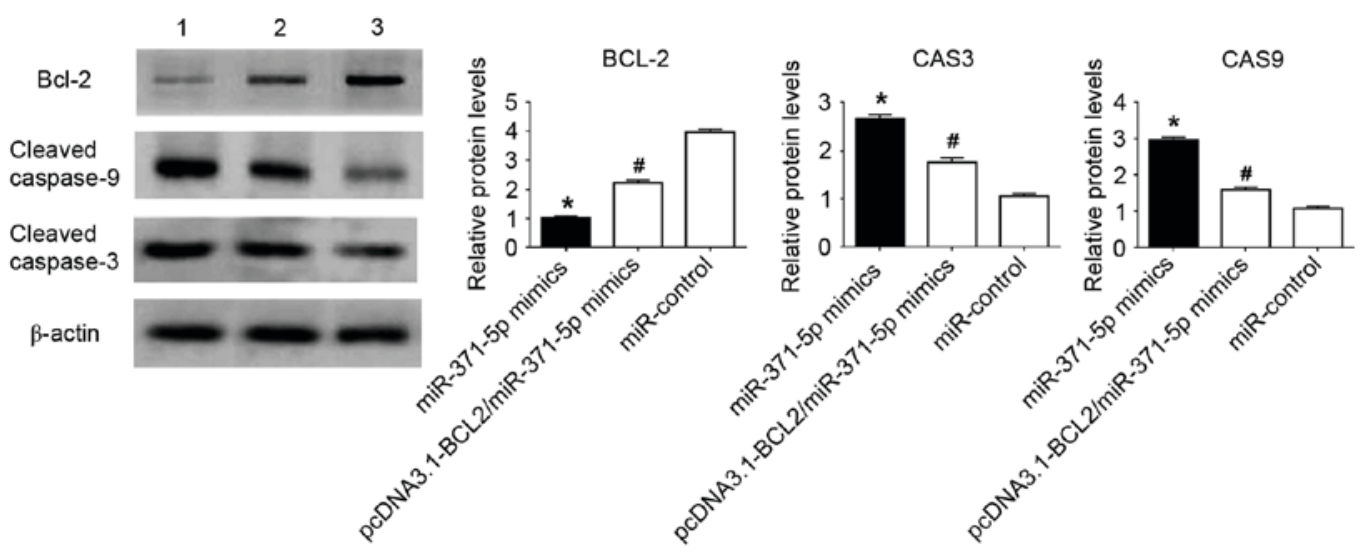

Figure 2. Flow cytometric analyses and western blot analysis of the effects of miR-371-5p on 5-8F cells. (A) miR-371-5p promoted 5-8F cell apoptosis. (B) miR-371-5p decreased the expression of BCL2, and increased the expression of cleaved caspase 3 and cleaved caspase 9 in 5-8F cells. Restoration of BCL-2 partially reversed the pro-apoptotic function of miR-371-5p. 1, miR-371-5p mimics; 2, miR-371-5p mimics/pcDNA3.1 vector containing BCL2; 3, miR-control. ${ }^{\text {"P }}<0.01$, vs. miR-control; " $\mathrm{P}<0.01$, vs. miR-371-5p mimics. miR, microRNA; BCL2, B-cell lymphoma 2; CAS3, caspase 3; CAS9, caspase 9; PI, propidium iodide. 
A

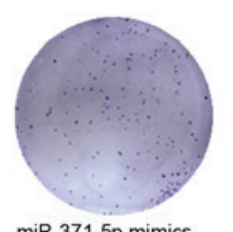

miR-371-5p mimics

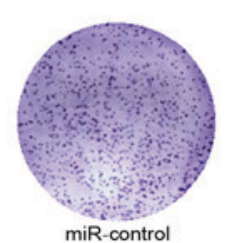

miR-control
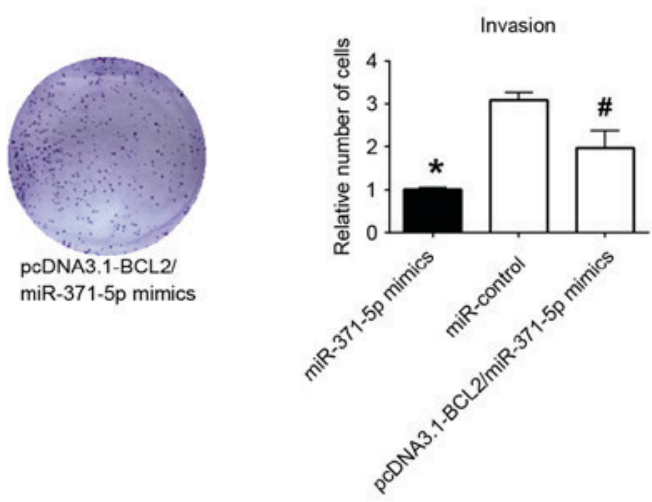

B

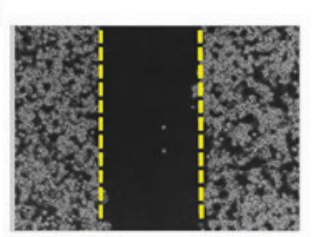

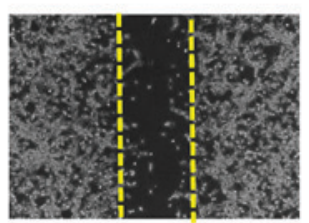

miR-371-5p mimics

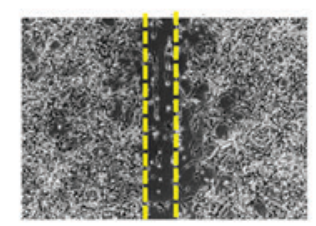

miR-control

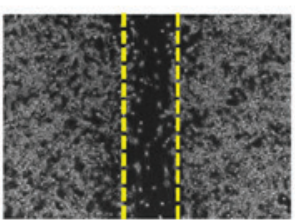

pCDNA3.1-BCL2/ miR-371-5p mimics

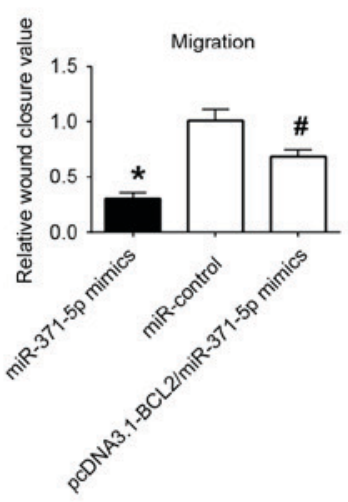

Figure 3. Transwell assays and wound healing assays to measure the effect of miR-371-5p on the metastatic ability of 5-8F cells. miR-371-5p inhibited the (A) invasion and (B) migration (magnification, $\mathrm{x} 40$ ) of $5-8 \mathrm{~F}$ cells. Restoration of BCL2 partially enhanced the metastatic ability of 5-8F cells transfected with miR-371-5p. ${ }^{*} \mathrm{P}<0.01$, vs. miR-control; ${ }^{*} \mathrm{P}<0.01$, vs. miR-371-5p mimics. miR, microRNA; BCL2, B-cell lymphoma 2.

A

$$
\begin{aligned}
& \text { Bcl-2(wt) 5'-UgaucguUuUcuguUugaga-3. } \\
& \text { I I |||||| } \\
& \text { miR-371-5p 3'-UCACGGGGGUGUCAAACUCA-5. } \\
& \text { Bcl-2 (mut) 5'- UGAUCGUUUUCUGGGGUCUA-3. }
\end{aligned}
$$

B

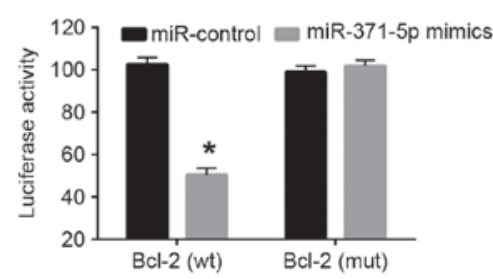

C

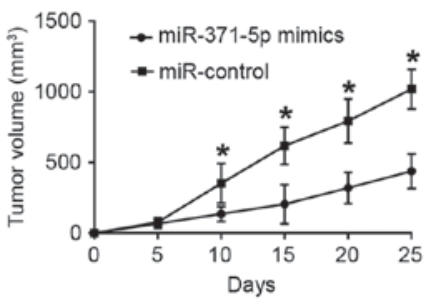

D

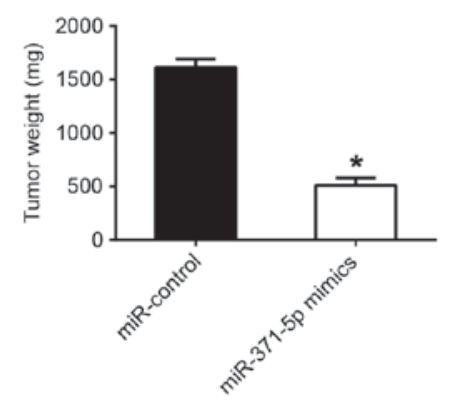

Figure 4. miR-371-5p can bind to the targeting sequence of BCL2 and inhibit tumor growth in vivo. (A) miR-371-5p and its predicted binding sequence for WT in the 3'-UTR of BCL2. (B) Luciferase reporter activity was reduced by miR-371-5p, compared with that in the miR-control group in the WT of BCL2, but no significant difference in activity was observed between the two groups in the mutant of the targeting sequence of BCL2. (C) miR-371-5p reduced the tumor volumes. (D) miR-371-5p reduced the tumor weights. "P<0.01, vs. miR-control. miR, microRNA; BCL2, B-cell lymphoma 2; WT, wild-type; Mut, mutant.

\section{Discussion}

As shown in previous studies, a number of genetic factors affect the evolution and growth of NPC, and miRs are an important factor (20). The BCL2 gene, an important anti-apoptotic gene, affects the intrinsic apoptotic pathway $(21,22)$. Bcl-2 can promote tumor invasion and it has been shown to enhance tumor growth and metastasis (23). Inhibition of the expression of BCL2 has been considered as an important treatment strategy for several types of cancer (24). However, the specific effects of miR-371-5p via modulation of the expression of BCL2 in the pathogenesis of NPC remain to be fully elucidated. 
The present study revealed important novel evidence that miR-371-5p has an important regulatory function on the expression of BCL2 in NPC cells. Firstly, the level of miR-371-5p was decreased in NPC patient samples and NPC cell lines. The downregulation of miR-371-5p was associated with the unfavorable clinicopathological features of patients. Secondly, a high expression level of miR-371-5p inhibited the growth and metastasis of $5-8 \mathrm{~F}$ cells. The upregulation of BCL-2 partially reversed the characteristics of $5-8 \mathrm{~F}$ cells induced by miR-371-5p with respect to proliferation and metastasis, as observed in previous studies $(25,26)$. Thirdly, the important function of miR-371-5p on $5-8 \mathrm{~F}$ cells via regulating the expression of BCL2 was confirmed using the luciferase reporter assay system and western blot analysis. Finally, these functions were identified using animal experiments, revealing the potential function of miR-371-5p on inhibiting NPC growth by targeting BCL2. miR-371-5p suppressed the expression of BCL2 by binding to the targeting sequence of BCL2. Cell apoptosis was significantly enhanced, and the growth and metastasis of NPC were inhibited by the upregulation of miR-371-5p.

In conclusion, the data obtained demonstrated that miR-371-5p decreased the level of BCL2, inhibited the development and metastasis of NPC, and provided a novel clue for understanding the underlying function of miR-371-5p in the pathogenesis of NPC. However, larger investigations assess the association between miR-371-5p and BCL2 in different types of tumor are required to further elucidate the precise molecular mechanisms.

\section{Acknowledgements}

Not applicable.

\section{Funding}

The present study was supported by the Science and Technology Project of Guangxi Zhuang Autonomous Region (grant no. 14279006).

\section{Availability of data and materials}

The datasets used during the current study are available from the corresponding author on reasonable request.

\section{Authors' contributions}

BD contributed to study design, data acquisition, statistical analysis, data interpretation, manuscript preparation, literature search and funding collection. FS contributed to data acquisition, literature search and manuscript preparation. RX contributed to data acquisition, statistical analysis and manuscript preparation. WT contributed to study design, data interpretation, manuscript preparation and funding collection.

\section{Ethics approval and consent to participate}

The Ethics Committee of Hezhou Renmin Hospital ratified all written agreement (approval no. 130201; Hezhou, China) according to the Declaration of Helsinki (2004). All patients expressed their full intentions to participate in the present study and a written consent form was obtained from each patient.

\section{Consent for publication}

Patient's information, including names, initials, date of birth or hospital numbers, images or statements have not been included in the manuscript. Meanwhile, the patient, or parent, guardian or next of kin have provided written informed consent for the publication of any associated data.

\section{Competing interests}

The authors declare that they have no competing interests.

\section{References}

1. Wei KR, Zheng RS, Zhang SW, Liang ZH, Ou ZX and Chen WQ: Nasopharyngeal carcinoma incidence and mortality in China in 2010. Chin J Cancer 33: 381-387, 2014.

2. Liu MT, Hsieh CY, Chang TH, Lin JP, Huang CC and Wang AY: Prognostic factors affecting the outcome of nasopharyngeal carcinoma. Jpn J Clin Oncol 33: 501-508, 2003.

3. Liang Z and Xi Y: MicroRNAs mediate therapeutic and preventive effects of natural agents in breast cancer. Chin J Nat Med 14: 881-887, 2016.

4. Xing Z, Li D, Yang L, Xi Y and Su X: MicroRNAs and anticancer drugs. Acta Biochim Biophys Sin (Shanghai) 46: 233-239, 2014.

5. Macfarlane LA and Murphy PR: MicroRNA: Biogenesis, function and role in cancer. Curr Genomics 11: 537-561, 2010.

6. Qin X, Chen J, Wu L and Liu Z: miR-30b-5p acts as a tumor suppressor, repressing cell proliferation and cell cycle in human hepatocellular carcinoma. Biomed Pharmacother 89: 742-750, 2017.

7. Wang L, Wu L and Wu J: Downregulation of miR-154 in human glioma and its clinicopathological and prognostic significance. J Int Med Res 44: 994-1001, 2016.

8. Tian F, Chen J, Zheng S, Li D, Zhao X, Jiang P, Li J and Wang S: miR-124 targets GATA6 to suppress cholangiocarcinoma cell invasion and metastasis. BMC Cancer 17: 175, 2017.

9. He B, Xu Z, Chen J, Zheng D, Li A and Zhang LS: Upregulated microRNA-143 inhibits cell proliferation in human nasopharyngeal carcinoma. Oncol Lett 12: 5023-5028, 2016.

10. Gao W, Lam JW, Li JZ, Chen SQ, Tsang RK, Chan JY and Wong TS: MicroRNA-138-5p controls sensitivity of nasopharyngeal carcinoma to radiation by targeting EIF4EBP1. Oncol Rep 37: 913-920, 2017.

11. Huang T, Yin L, Wu J, Gu JJ, Wu JZ, Chen D, Yu HL, Ding K, Zhang N, Du MY, et al: MicroRNA-19b-3p regulates nasopharyngeal carcinoma radiosensitivity by targeting TNFAIP3/NF-kB axis. J Exp Clin Cancer Res 35: 188, 2016.

12. Li Y, Lv Z, He G, Wang J, Zhang X, Lu G, Ren X, Wang F, Zhu X, Ding Y, et al: The SOX17/miR-371-5p/SOX2 axis inhibits EMT, stem cell properties and metastasis in colorectal cancer. Oncotarget 6: 9099-9112, 2015.

13. He D, Miao H, Xu Y, Xiong L, Wang Y, Xiang H, Zhang H and Zhang Z: miR-371-5p facilitates pancreatic cancer cell proliferation and decreases patient survival. PloS One 9: e112930, 2014.

14. Liu RY, Diao CF, Zhang Y, Wu N, Wan HY, Nong XY, Liu M and Tang H: miR-371-5p down-regulates pre mRNA processing factor 4 homolog B (PRPF4B) and facilitates the G1/S transition in human hepatocellular carcinoma cells. Cancer Lett 335: 351-60, 2013.

15. Igney FH and Krammer PH: Immune escape of tumors: Apoptosis resistance and tumor counterattack. J Leukoc Boil 71: 907-920, 2002.

16. Lessene G, Czabotar PE and Colman PM: BCL-2 family antagonists for cancer therapy. Nat Rev Drug Discov 7: 989-1000, 2008.

17. Bajwa N, Liao C and Nikolovska-Coleska Z: Inhibitors of the anti-apoptotic Bcl-2 proteins: A patent review. Expert Opin Ther Pat 22: 37-55, 2012. 
18. Fendri A, Kontos CK, Khabir A,Mokdad-Gargouri R, Ardavanis A and Scorilas A: Quantitative analysis of BCL2 mRNA expression in nasopharyngeal carcinoma: An unfavorable and independent prognostic factor. Tumour Boil 31: 391-399, 2010.

19. Livak KJ and Schmittgen TD: Analysis of relative gene expression data using real-time quantitative PCR and the 2(-Delta Delta C(T)) method. Methods 25: 402-408, 2001.

20. Gomes BC, Rueff J and Rodrigues AS: MicroRNAs and cancer drug resistance. Methods Mol Biol 1395: 137-162, 2016.

21. Cory S, Huang DC and Adams JM: The Bcl-2 family: Roles in cell survival and oncogenesis. Oncogene 22: 8590-8607, 2003.

22. Hockenbery D, Nunez G, Milliman C, Schreiber RD and Korsmeyer SJ: Bcl-2 is an inner mitochondrial membrane protein that blocks programmed cell death. Nature 348: 334-336, 1990.

23. Choi J, Choi K, Benveniste EN, Rho SB, Hong YS, Lee JH, Kim J and Park K: Bcl-2 promotes invasion and lung metastasis by inducing matrix metalloproteinase-2. Cancer Res 65: 5554-5560, 2005 .
24. Sheng H, Shao J, Morrow JD, Beauchamp RD and DuBois RN: Modulation of apoptosis and $\mathrm{Bcl}-2$ expression by prostaglandin E2 in human colon cancer cells. Cancer Res 58: 362-366, 1998.

25. He CY and Yang J: miR-187 induces apoptosis of SiHa cervical carcinoma cells by downregulating Bcl-2. Genet Mol Res 16: gmr16018969, 2017.

26. Ma Z, Luo Y and Qiu M: miR-143 Induces the apoptosis of prostate cancer LNCap cells by suppressing Bcl-2 expression. Med Sci Monit 23: 359-65, 2017.

(c) (i) $(9$ This work is licensed under a Creative Commons

(cY No No Attribution-NonCommercial-NoDerivatives 4.0 International (CC BY-NC-ND 4.0) License. 